\title{
Sanitation for all: the global opportunity to increase transgenerational health gains and better understand the link between NCDs and NTDs, a scoping review
}

Shiva Raj Mishra ${ }^{1,2^{*}}$, Meghnath Dhimal ${ }^{3,4}$, Parash Mani Bhandari ${ }^{5}$ and Bipin Adhikari ${ }^{6}$

\begin{abstract}
The global sanitation divide is narrowing. However, in many countries in Asia and Africa, the gap between rural and urban sanitation coverage is rather widening. Moreover, there is an increase in the burden of non-communicable diseases (NCDs), notwithstanding to the already high burden of neglected tropical diseases (NTDs). A scientific query is building on how the global 'sanitation for all' goal will address the dual burden of NTDs and NCDs, and help further understand the link between the two. This paper aims to discuss the link between i) sanitation and NTDs, and ii) sanitation and NCDs through a scoping review of the literature.
\end{abstract}

Keywords: Neglected-tropical diseases, Non-communicable diseases, Chronic diseases, Asia, Africa, Sanitation

\section{Background}

The global division in 'sanitation for all' is closing with studies showing $47 \%$ of people in South Asia and 30\% of them in Sub-Saharan Africa in 2015 have achieved basic sanitation facilities compared to the baseline average of $22 \%$ and $24 \%$ respectively in 1990 [1]. Globally, this change equals to an increase in improved sanitation coverage from $54 \%$ in 1990 to $68 \%$ in 2015 , and in the least developed countries, increase in sanitation coverage from $20 \%$ in 1990 to $38 \%$ in 2015 [1]. Despite this global progress, 950 million people, mostly those in low and middle-income countries (LMICs), defecated in the open in 2015.

Among the people without access to improved sanitation, seven of ten were rural inhabitants. In some parts of LMICs, the rural and urban sanitation gap is rather widening, with rural areas deprived of adequate sanitation facilities. In India, the number of people without improved sanitation has declined marginally $(10 \%$ of urban

\footnotetext{
*Correspondence: shivarajmishra@gmail.com; nedsnepal@gmail.com; http://www.nedsnepal.org

${ }^{1}$ Nepal Development Society, P.O.Box. 75, Bharatpur-10, Nepal

${ }^{2}$ School of Population Health, University of Western Australia, Perth, WA

6009, Australia

Full list of author information is available at the end of the article
}

inhabitants in 2015 compared to $29 \%$ in 1990 defecated in open areas while $61 \%$ rural inhabitants in 2015 compared to $91 \%$ in 1990 defecated in open areas) [2]. Due to inadequate sanitation, there is a wide spectrum of effects on maternal and child health, from water contaminations, resulting in diarrheal diseases including cholera and other gastrointestinal infections [3, 4]. While the spectrum of effects of inadequate sanitation so far has been established to affect the Neglected Tropical Diseases (NTDs) and communicable diseases, some studies have shown the link between inadequate sanitation and chronic noncommunicable diseases (NCDs) through soil-transmitted helminths (STH) and other infections [5], and through other possible mechanisms. This observed link bridges the relationship between sanitation and NCDs and is discussed here in this article.

\section{Methods}

The method chosen for this review uses the principles and practices of a scoping review [6, 7]. A scoping review principally includes the following five phases: i) formulating a research question, ii) identifying relevant studies, iii) selection of studies, iv) extracting and analysing results, and v) summarising and reporting the results. Using the several combinations of search terms: "sanitation", 
"hygiene", "WASH", "non-communicable diseases", "chronic diseases", "neglected tropical diseases" and "lowincome country", literature search was carried out in PubMed/Medline and Google Scholar without limiting the search to language or study year. A total of 18 studies were obtained for Panel 1 (Review on the link between sanitation and NTDs), and 50 studies for Panel 2 (Review on the link between sanitation and NCDs). Further, we made an online post in ResearchGate (http://tinyurl.com/ NCDsandNTDs) asking researchers to post published or unpublished studies, that they were aware of, on the link between NCDs and NTDs. Doing so, we identified ten additional papers which were later incorporated in Panel 2 of this paper.

\section{Main Text}

Inadequate Sanitation and Health

Some scholars like Sunita Narain correctly said that "rapidly-modernizing India is drowning in its own excreta" [8]. According to her estimates, little more than $33 \%$ of rural population in India compared to the $87 \%$ of city population have access to a toilet in India. However, having a toilet is not enough in itself. Inadequate management of excreta is another problem in many cities in India. This has been a common challenge in other LMICs as well.

The continuum of sewer management from having adequate sanitation facilities to adequate sewer treatment facilities is critical. Other researchers such as Abhishek Sharma advocate that economic benefits can be gained by improving sanitation coverage, asking for the commercialization of human excreta as a 'business investment' in Indian railways by building small biogas plants in trains or at stations [9]. The economic gains from having improved sanitation coverage have not been a topic of serious discussion among policy makers, and there has largely been a lack of interest in health leaders and health researchers to explore the health benefits of having and using toilets every day. However, the previous estimation states that every dollar spent in universal access to sanitation in countries not in Organisation for Economic Co-operation and Development will pay back 11.2 dollars [10].

In Panel 1, we summarise the link between NTDs and sanitation.

\section{Panel 1: Review on the link between sanitation and NTDs}

NTDs are a group of chronic (disabling) diseases affecting more than a billion people residing in 149 countries worldwide, but most of these affect the poorest of the poor (bottom billion of the earth's population) in regions with tropical and subtropical climates [11, 12]. It is estimated that for every dollar invested in NTD control, there will be an increase in economic productivity by 50 folds [13]. Often these diseases are called "neglected" because they are not prioritised in terms of control and funding as compared to the "big three" diseases - HIV/AIDS, malaria, and tuberculosis. However, in regards to mortality, one NTD alone kills more young children each year than all "big three" diseases combined [14].

The World Health Organization (WHO) has so far listed 17 diseases under its NTD programme: dengue fever, chikungunya fever, rabies, trachoma, buruli ulcer (i.e., Mycobacterium ulcerans infection), leprosy (Mycobacterium leprae infection), chagas disease (American trypanosomiasis), human African trypanosomiasis (sleeping sickness), leishmaniasis, cysticercosis, dracunculiasis (guinea-worm disease), echinococcosis, food-borne trematode infections, lymphatic filariasis, onchocerciasis (river blindness), schistosomiasis (bilharziasis), and soiltransmitted helminthiases [11].

According to the Global Burden of Disease Study 2010, the estimated disability-adjusted life years (DALYs) of these NTDs alone were 23.06 (95\% CI: 20.30-35.12) million [15]. However, the real burden of NTDs in many regions and countries, especially in LMICs such as Nepal, is underreported. This is particularly due to the dysfunctional data collection system at the primary health care level and the unavailability of funding for research [16-18]. For the prevention of NTDs through sanitation, safe water, and hygiene (WASH) related programs, WHO has formulated a Global Strategy on 'Water, Sanitation and Hygiene for accelerating and sustaining progress on Neglected Tropical Diseases'. A vicious circle of poverty and disease is contributed by NTDs which further adds burden to the already stretched health systems [19].

About one-third of the world's population (2.4 billion) lacks access to adequate sanitation, one billion people practice open defecation, and 663 million do not have access to improved sources of drinking water [20]. Among the NTDs, schistosomiasis, trachoma and STH are strongly associated with WASH. The association of NTDs with WASH has been substantiated by some systematic reviews and meta-analyses [21-23]. Another study reports that better hygiene in children was associated with lower odds of trachomatous infection [22]. Similarly, WASH access and practice were associated with 33-70\% lower odds of STH infection [23].

For prevention and treatment of many NTDs, WASH interventions play a critical role. For effective WASH interventions, there is an urgent need for inter-sectoral collaboration. WHO has recommended an integrated approach to overcome the global impact of NTDs through five interventions on the path to universal coverage: innovative and intensified disease management; preventive chemotherapy; studies on vector 
ecology and management; veterinary public health services; and the provision of safe WASH [11]. For instance, international efforts to eliminate trachoma as a blinding disease has been successfully implemented in many countries based on the WHO - developed SAFE strategy which stands for surgery for trichiasis, antibiotics, facial cleanliness and environmental improvement [24, 25].

Description of the role of WASH in schistosomiasis, trachoma and STH prevention and control is provided below:

Schistosomiasis is caused by infection with parasitic blood flukes. People become infected when they come into contact with water bodies harbouring freshwater snails that have been infected with urine and faeces of infected people. The eggs of these parasites cause extensive damage to tissues and organs which can result in chronic infection and if untreated can lead to death. It is estimated that worldwide, nearly 250 million people are at risk of schistosomiasis [26]. The eggs of the parasites causing schistosomiasis are shed by infected individuals through the faeces and urine, which if deposited in surface water, contaminate the water and infect snails. People who are at high risk (those who bathe, wash clothes or work in the water) acquire larvae released from the snail which enters into the human skin [27]. Hence community-based sanitation facilities are essential to prevent contamination of water bodies with urine and faeces and infection of schistosomiasis.

Trachoma is an infectious eye disease caused by bacterium $C$. trachomatis and is the leading cause of preventable blindness worldwide. Infection is caused by black flies that breed in human faeces and can contaminate humans by fingers, hands, clothing, or discharge from the eyes and nose of an infected individual. The population at risk of trachoma is estimated at 229 million [28]. Key hygiene activities to prevent trachoma include promoting regular face washing with soap to remove eye and nasal discharge contaminated with bacteria as well as promoting regular washing of clothing and bedding with soap. Sanitation interventions include encouraging communities to reduce open defecation, increasing access to and use of household toilets to minimise open defecation deposits near the home and promoting latrine maintenance. Improving access to clean water, which can lead to adequate water use for household hygiene practices (face washing and washing of clothing and bedding), can intercept the spread of disease [27].

Soil-transmitted helminths refer to a group of parasites (roundworm, whipworm, and hookworm) that live in the soil in warm and humid climates, spread through physical contact with faeces of infected people, and survive in the human digestive system. It is estimated that 1 billion people are infected with STH or are at risk of infection worldwide. STH infection can cause blood loss leading to anaemia, nutritional deficiencies and thus is harmful in particular to children and women of childbearing age.

It is estimated that over one billion people are at risk of infection with STH, including over 800 million children worldwide [26]. Key hygiene and sanitation interventions for prevention and control of STH include promoting hand washing before eating, after working, and after defecation; promoting proper disposal of infant/child feces; promoting wearing shoes when walking outside; reducing open defecation to minimize soil contamination; ensuring access to a household latrine and toilets in schools to minimize open defecation and; ensuring that processes are in place for regular cleaning and maintenance of toilets [27].

\section{Sanitation Links with NCDs}

NCDs in the $21^{\text {st }}$ century are the leading killer diseases which contribute to 38 million deaths every year, and nearly three-quarter of these deaths occurs in LMICs. Also, nearly $42 \%$ of total NCD related deaths occur in people below the age of 70 [29]. Development of NCDs is multifactorial and is largely the result of lifestyle factors. Also, its link with NTDs is emerging as a new area for scientific enquiry. The early diagnosis of NTDs will have a dual advantage over late diagnosis and management. It can be a portal of entry for NCD screening and management because many of such NCDs are commonly prevalent among people with NTDs and are routinely diagnosed at primary health care level. Without further studies, we are not in the position to say comorbidities in NTDs are the result of NTDs because the pathological basis of NCDs manifestation in NTDs is miles away from the adequate explanation. NCDs are manifested in the cases of NTDs at the later stage of its prognosis, which may not be directly due to NTDs itself, but due to late outcomes of the diseases or the complications arising due to late health seeking behaviour.

In Panel 2, we present a summary of the link between NCDs and sanitation. Based on our cursory literature review, we also enlist some evidence on possible explanations for the links presented.

\section{Panel 2: Review on the link between sanitation and NCDs \\ Cancer}

The release of eggs into the fresh water bodies and consumption of raw fish are the two poor sanitary practices that are reported to facilitate the transmission of Opisthorchis species from their first intermediate hostsnail to second intermediate host-fish and at the end to 
the final host-human [30]. Opisthorchis infestation is documented to be linked with cholangiocarcinoma [31, 32]. In experimental studies on the liver of golden hamsters, researchers observed the development of cholangiocarcinoma from the chronic infestation of Opisthorchis [33, 34]. However, controlled trials carried out among the human population are lacking.

In addition to Opisthorchis infestation, studies have also linked Clonorchis infestation with cholangiocarcinoma [32, 35-40]. Liver fluke induced chronic inflammation coupled with some specific microRNAs may explain the carcinogenesis from Opisthorchis or Clonorchis infection $[41,42]$.

Additionally, the chronic infection of schistosomiasis is documented to induce the metaplasia of transitional epithelial cells $[43,44]$ and to be a risk factor for the development of bladder cancer [45, 46]. T-helper 2 (Th2) type immune response instigated by Schistosoma or genetic polymorphisms mostly due to chronic infection may be a possible explanation for this carcinogenesis $[47,48]$.

Not only worms but also fungal species are reported to be associated with cancer. Chromoblastomycosis, a fungal infection more common in people with poor hygiene and inappropriate clothing or footwear [49], is observed to have an association with squamous cell carcinoma [50, 51]. However, the pathogenesis for the development of carcinoma from chromoblastomycosis is not well-understood.

\section{Diabetes}

Trypanosoma cruzi, a parasite, is reported to enter from faeces of triatomine, an insect vector, into the human body through the mucous membrane or cracks in skin, and cause chagas disease. This illness is common among residents of areas with improper sanitation and poor housing [52]. The risk of development of diabetes is observed to be higher in women with chagas cardiomyopathy than those with chagas disease alone [53]. This may be due to the physiological and morphological changes in pancreas from chagas disease [54, 55].

Similarly, leprosy is transmitted via contact with nasal fluid infected with Mycobacterium leprae or Mycobacterium lepromatosis $[56,57]$ in the absence of adequate sanitation [58]. As reported by a study, in comparison to people without leprosy, the prevalence of diabetes is greater in people with such illness [59]. This may be due to high levels of pro-inflammatory cytokines such as TNFo [59] which induces insulin resistance in people with leprosy [60].

However, Schistosoma infection is reported to provide the protective effect against diabetes [61]. Similar to this, infestation of other soil-transmitted helminths, worms that harbour in filthy soils, are observed to have a protective effect against diabetes $[62,63]$. This protective effect against diabetes may be due to activation of Th2 response, eosinophilia, and waist adipose tissue M2 polarisation from helminth infection $[64,65]$.

\section{Portal hypertension}

Patients with schistosomiasis often develop portal hypertension [66]. This may be due to induction of osteopontin production by the eggs of Schistosoma which increases the severity of liver fibrosis [67].

\section{Cardiomyopathy}

Development of cardiomyopathy is reported in the person with chagas disease [68]. Progression of chagas disease to cardiomyopathy is characterised by parasite-mediated injuries [69], immunological reactions [70], and microvascular damages [71].

In addition to this, serological tests have revealed the association of Toxoplasma infection with cardiomyopathy [72]. Macrophage production by cytokine activation [73] and production of IFN- $\gamma$ and interleukin-12 [74, 75] are documented to be possible causes for the development of cardiomyopathy after Toxoplasma infection.

\section{Chronic kidney disease and renal failure}

Chronic kidney disease, and often renal failure is observed in a person with schistosomiasis [76]. Schistosomiasis results in immune-complex mediated reactions [77] or activation of polyclonal B-lymphocytes [78], which may be responsible for the chronic kidney disease or renal failure.

\section{Asthma}

Transmission of Toxocora from cats or dogs to human occurs from contact with their faeces. Lack of proper sanitation \& hygiene makes a person susceptible to Toxocora infection [79], an infection which is associated with asthma [80]. This association may be due to the induction of Th2 immunity after a Toxocora infestation that triggers chronic allergic manifestations, finally leading to asthma [81].

Similarly, dust mites and respiratory infection by chlamydia or influenza virus, all of which groom in the absence of adequate hygiene, are also linked with chronic asthma [82, 83]. These links may be explained by the production of agent specific IgE after the infection $[84,85]$, which subsequently develops into a chronic asthma.

\section{Acute myocardial infarction}

Acute respiratory infection, an infection that may be exacerbated by poor sanitation [86], is documented as a risk factor for acute myocardial infarction [87]. The risk of acute myocardial infarction from acute respiratory infection may be due to the increased concentration of C-reactive protein [88], or inflammatory cytokines [89], or platelet activation [90]. 


\section{Global strides in 'sanitation for all'}

A great stride has been achieved in 'sanitation for all' in recent years in LMICs despite public apathy to discuss or even talk about toilets. It is largely deliberated by the works of international organisations like United Nations Population Fund (UNFPA). For example, UNFPA has been conducting open defecation free campaigns in 30 districts of Nepal. From sanitation coverage of one percent, 25 years ago to 76\% in 2014, Nepal has made a big stride in sanitation coverage. Fifteen districts, of Nepal's 75 districts, were labelled open defecation free (ODF) in 2014, and another 15 are in the process of achieving that status [91]. Similar progress has been achieved in many other countries such as Bangladesh, Pakistan and India which have achieved a $30 \%$ or greater drop in population in ODF zones since the 1990s [1].

With the adoption of SDGs, the global goals have shifted from narrowly defined health goals to broader social goals. That includes 'sanitation for all' leading to sustainable development. Inadequate sanitation cannot be a choice, as it leads to social deprivation of rights and lack of access to toilets, which consequently increases the disease burden. SDGs should pivot the agenda of 'sanitation for all' to other SDGs and global goals on maternal and child health, and NCDs for the sustainable development and health of individual and society.

A greater involvement of civil society and the community is needed in both NTDs and NCDs related programs. Rather than a top-down project, a community-led project with a greater community ownership and engagement holds promise [92]. Securing the community's initiative to plan, execute and supervise can be a more sustainable solution than vertical efforts of implementation where a community may feel obliged, marginalised or even neglected $[92,93]$. Nonetheless, engaging communities for such projects requires a stepwise process of selecting the community leaders, training them, providing required resources, supervising them with additional training, resources and finally monitoring the activities with transparent performance data [93].

Finally, 'sanitation for all' appears to be not just the cure for many NTDs, but also many NCDs. However, existing evidence does not give us much confidence to discuss the benefits with certainty particularly on NCDs control and management. Future studies should explore dual benefits of sanitation coverage on NTDs and NCDs.

\section{Conclusions}

This qualitative review is an attempt to document the health effects of inadequate sanitation from theoretical perspectives, with its link with NCDs and NTDs and global strides for 'sanitation for all'. The current research gaps demands for more systematic reviews which can quantify health effects, economic effects and guide for the policy for the goal of sanitation. The global strides in 'sanitation for all' are welcoming, however, there are challenges to integrating sanitation with lifestyle in LMICs. In particular, the effect of inadequate sanitation and its effect in NCDs is poorly understood to this date. Without a doubt, investing in sanitation is a primary prevention for many diseases and conditions and is a great investment for mankind in the $21^{\text {st }}$ century. Greater investment with community engagement, strong commitment to global goals and newer strategies for 'sanitation for all' are urgently needed.

\section{Abbreviations}

LMICs: Low and Middle-Income Countries; NCDs: Non-Communicable Diseases; NTDs: Neglected Tropical Diseases; SDGs: Sustainable Development Goals; WHO: World Health Organization

\section{Acknowledgement}

We sincerely express our gratitude to Mr Gordon Tambellini for his constructive feedbacks and inputs in final proof of the paper.

\section{Funding}

No specific funding received for this work.

Availability of data and material

Not applicable.

\section{Authors' contributions}

SRM, BA and MD conceptualised this paper. MD drafted Panel 1 and PMB drafted Panel 2. All the authors contributed to the revision of the paper. All authors read and approved the final paper.

\section{Competing interests}

The authors declare that they have no competing interests.

Consent for publication

All the authors have consented the paper for publication.

Ethics approval and consent to participate

Not applicable

\section{Publisher's Note}

Springer Nature remains neutral with regard to jurisdictional claims in published maps and institutional affiliations.

\section{Author details}

${ }^{1}$ Nepal Development Society, P.O.Box. 75, Bharatpur-10, Nepal. ${ }^{2}$ School of Population Health, University of Western Australia, Perth, WA 6009, Australia. ${ }^{3}$ Nepal Health Research Council (NHRC), Ramshah Path, Kathmandu, Nepal. ${ }^{4}$ Institute of Occupational Medicine, Social Medicine and Environmental Medicine, Goethe University, Frankfurt am Main, Germany. ${ }^{5}$ Maharajgunj Medical Campus, Institute of Medicine, Kathmandu, Nepal. ${ }^{6}$ Mahidol-Oxford Tropical Medicine Research Unit, Faculty of Tropical Medicine, Mahidol University, Bangkok, Thailand.

Received: 7 September 2016 Accepted: 11 April 2017

Published online: 26 April 2017

\section{References}

1. UNICEF. Progress on Sanitation and Drinking-Water: 2015 Update and MDG Assessment. Geneva: World Health Organization; 2015.

2. UNICEF. The world has missed the MDG sanitation target by almost 700 million USA: Unicef. 2015. http://www.data.unicef.org/water-sanitation/ sanitation.html. Accessed 5 Aug 2016.

3. Mara D, Lane J, Scott B, Trouba D. Sanitation and health. PLoS Med. 2010;7(11):e1000363. 
4. Wolf J, Pruss-Ustun A, Cumming O, Bartram J, Bonjour S, Cairncross S, Clasen T, Colford Jr JM, Curtis V, De France J, et al. Assessing the impact of drinking water and sanitation on diarrhoeal disease in low- and middle-income settings: systematic review and meta-regression. Trop Med Int Health. 2014;19(8):928-42.

5. Hays R, Esterman A, McDermott R. Type 2 diabetes mellitus is associated with Strongyloides stercoralis treatment failure in Australian aboriginals. PLoS Negl Trop Dis. 2015:9(8):e0003976.

6. Mishra SR, Neupane D, Bhandari PM, Khanal V, Kallestrup P. Burgeoning burden of non-communicable diseases in Nepal: a scoping review. Glob Health. 2015;11:32.

7. Pham MT, Rajic A, Greig JD, Sargeant JM, Papadopoulos A, McEwen SA. A scoping review of scoping reviews: advancing the approach and enhancing the consistency. Res Synth Methods. 2014;5(4):371-85.

8. $\quad$ Narain S. Sanitation for all. Nature. 2012;486(7402):185.

9. Sharma A, Unnikrishnan MK, Madaan A. Toilet technology: Improve sanitation on India's railways. Nature. 2012:489(7414):33.

10. Van Minh $H$, Nguyen-Viet $H$. Economic aspects of sanitation in developing countries. Environ Health Insights. 2011;5:63-70.

11. WHO. Third WHO report on neglected tropical diseases: Investing to overcome the global impact of neglected tropical diseases. Geneva: WHO; 2015.

12. Hotez PJ, Fenwick A, Savioli L, Molyneux DH. Rescuing the bottom billion through control of neglected tropical diseases. Lancet. 2009;373(9674):1570-5.

13. The END Fund. NTD Efforts Deliver an Unparallelled Return on Investment. 2016. https://www.end.org/docs/default-source/default-document-library/ end-fund-ntd-fact-sheet_may-2016.pdf?sfvrsn=2. Accessed 18 Apr 2017.

14. Bartram J, Cairncross S. Hygiene, sanitation, and water: forgotten foundations of health. PLOS Med. 2010;7(11):e1000367.

15. Hotez PJ, Alvarado M, Basanez MG, Bolliger I, Bourne R, Boussinesq M, Brooker SJ, Brown AS, Buckle G, Budke CM, et al. The global burden of disease study 2010: interpretation and implications for the neglected tropical diseases. PLoS Negl Trop Dis. 2014;8(7):e2865.

16. Hotez PJ, Alibek K. Central Asia's hidden burden of neglected tropical diseases. PLoS Negl Trop Dis. 2011;5(9):e1224.

17. Dhimal M, Karki KB. The hidden burden of Neglected Tropical Diseases: a call for inter-sectoral collaboration in Nepal. J Nepal Health Res Counc. 2014;12(28):I-IV.

18. Raut S, Adhikari B. Global leadership against antimicrobial resistance ought to include developing countries. Lancet Infect Dis. 2016;16(7):775.

19. WHO. Water, Sanitation and Hygine for acceplerating and sustaining progress towards neglected tropical diseases: A Global Stategy 2015-2020. Geneva: WHO; 2015

20. WHO/UNICEF. Progress on Drinking Water and Sanitation: 2015 update and MDG assessment. Geneva: WHO; 2015.

21. Grimes JE, Croll D, Harrison WE, Utzinger J, Freeman MC, Templeton MR. The relationship between water, sanitation and schistosomiasis: a systematic review and meta-analysis. PLoS Negl Trop Dis. 2014;8(12):e3296.

22. Stocks ME, Ogden S, Haddad D, Addiss DG, McGuire C, Freeman MC. Effect of water, sanitation, and hygiene on the prevention of trachoma: a systematic review and meta-analysis. PLoS Med. 2014;11(2):e1001605.

23. Strunz EC, Addiss DG, Stocks ME, Ogden S, Utzinger J, Freeman MC. Water, sanitation, hygiene, and soil-transmitted helminth infection: a systematic review and meta-analysis. PLoS Med. 2014;11(3):e1001620.

24. Emerson PM, Burton M, Solomon AW, Bailey R, Mabey D. The SAFE strategy for trachoma control: Using operational research for policy, planning and implementation. Bull World Health Organ. 2006;84(8):613-9.

25. Emerson P, Kollmann M, MacArthur C, Bush S, Haddad D. SAFE strategy for blinding trachoma addresses sanitation, the other half of MDG7. Lancet. 2012;380(9836):27-8

26. World Health Organization. Neglected tropical diseases. Geneva: 2016. http://www.who.int/neglected_diseases/preventive_chemotherapy/sth/en/. Accessed 12 Nov 2016

27. Ogden S, Gallo K, Davis S, McGuire C, Meyer E, Addiss D, Haddad D. WASH and the Neglected Tropical Disease: A Global Manual for WASH Implementers. Atlanta: Sightsavers; 2013.

28. World Health Organization. Global Alliance for the Elimination of Blinding Trachoma by, 2020. Wkly Epidemiol Rec. 2013;88(24):242-51.

29. Mendis S. Global status report on noncommunicable diseases 2014: World Health Organization. 2014. http://apps.who.int/iris/bitstream/10665/148114/ 1/9789241564854_eng.pdf?ua=1. Accessed 10 Nov 2016.
30. Chai JY, Darwin Murrell K, Lymbery AJ. Fish-borne parasitic zoonoses: status and issues. Int J Parasitol. 2005;35(11-12):1233-54.

31. Sriamporn S, Pisani P, Pipitgool V, Suwanrungruang K, Kamsa-ard S, Parkin DM. Prevalence of Opisthorchis viverrini infection and incidence of cholangiocarcinoma in Khon Kaen, Northeast Thailand. Trop Med Int Health. 2004;9(5):588-94

32. Sripa B, Kaewkes $S$, Sithithaworn P, Mairiang E, Laha T, Smout M, Pairojkul C, Bhudhisawasdi V, Tesana S, Thinkamrop B, et al. Liver Fluke Induces Cholangiocarcinoma. PLoS Med. 2007;4(7):e201.

33. Thamavit W, Bhamarapravati N, Sahaphong S, Vajrasthira S, Angsubhakorn S. Effects of dimethylnitrosamine on induction of cholangiocarcinoma in Opisthorchis viverrini-infected Syrian golden hamsters. Cancer Res. 1978; 38(12):4634-9.

34. Thamavit W, Kongkanuntn R, Tiwawech D, Moore MA. Level of Opisthorchis infestation and carcinogen dose-dependence of cholangiocarcinoma induction in Syrian golden hamsters. Virchows Arch B Cell Pathol Incl Mol Pathol. 1987:54(1):52-8.

35. Hou PC. The relationship between primary carcinoma of the liver and infestation with Clonorchis sinensis. J Pathol Bacteriol. 1956;72(1):239-46.

36. Hou PC, Pang SC. Chorionepithelioma: an analytical study of 28 necropsied cases, with special reference to the possibility of spontaneous retrogression. J Pathol Bacteriol. 1956;72(1):95-104.

37. Hou PC. Primary carcinoma of bile duct of the liver of the cat (Felis catus) infested with Clonorchis sinensis. J Pathol Bacteriol. 1964;87:239-44.

38. Sher L, Iwatsuki S, Lebeau G, Zajko AB. Hilar cholangiocarcinoma associated with clonorchiasis. Dig Dis Sci. 1989;34(7):1121-3.

39. Ona FV, Dytoc JN. Clonorchis-associated cholangiocarcinoma: a report of two cases with unusual manifestations. Gastroenterology. 1991;101(3):831-9.

40. Shin HR, Lee CU, Park HJ, Seol SY, Chung JM, Choi HC, Ahn YO, Shigemastu T. Hepatitis B and C virus, Clonorchis sinensis for the risk of liver cancer: a case-control study in Pusan, Korea. Int J Epidemiol. 1996;25(5):933-40.

41. Jusakul A, Kongpetch S, Teh BT. Genetics of Opisthorchis viverrini-related cholangiocarcinoma. Curr Opin Gastroenterol. 2015;31(3):258-63.

42. Plieskatt J, Rinaldi G, Feng Y, Peng J, Easley S, Jia X, Potriquet J, Pairojkul C, Bhudhisawasdi V, Sripa B, et al. A microRNA profile associated with Opisthorchis viverrini-induced cholangiocarcinoma in tissue and plasma. BMC Cancer. 2015:15:309.

43. Wright CA: The Schistosome Life-Cycle. In: Bilharziasis: International Academy of Pathology · Special Monograph. edn. Edited by Mostofi FK. Berlin, Heidelberg: Springer Berlin Heidelberg; 1967: 3-7

44. Khurana S, Dubey ML, Malla N. Association of parasitic infections and cancers. Indian J Med Microbiol. 2005;23(2):74-9.

45. IARC. Schistosomes, liver flukes and Helicobacter pylori. IARC Working Group on the Evaluation of Carcinogenic Risks to Humans. Lyon, 7-14 June 1994. IARC Monogr Eval Carcinog Risks Hum. 1994;61:1-241.

46. Vizcaino AP, Parkin DM, Boffetta P, Skinner ME. Bladder cancer: epidemiology and risk factors in Bulawayo, Zimbabwe. Cancer Causes Control. 1994;5(6):517-22.

47. Bernardo C, Cunha MC, Santos JH, da Costa JM, Brindley PJ, Lopes C, Amado F, Ferreira R, Vitorino R, Santos LL. Insight into the molecular basis of Schistosoma haematobium-induced bladder cancer through urine proteomics. Tumour Biol. 2016:37:11279.

48. Goerlitz D, Amr S, Dash C, Saleh DA, El Daly M, Abdel-Hamid M, El Kafrawy S, Hifnawy T, Ezzat S, Abdel-Aziz MA, et al. Genetic polymorphisms in NQO1 and SOD2: interactions with smoking, schistosoma infection, and bladder cancer risk in Egypt. Urol Oncol. 2014;32(1):47.e15-20.

49. Londero AT, Ramos CD. Chromomycosis: a clinical and mycologic study of thirty-five cases observed in the hinterland of Rio Grande do Sul, Brazil. Am J Trop Med Hyg. 1976;25(1):132-5.

50. Azevedo CM, Marques SG, Santos DW, Silva RR, Silva NF, Santos DA Resende-Stoianoff MA. Squamous cell carcinoma derived from chronic chromoblastomycosis in Brazil. Clin Infect Dis. 2015;60(10):1500-4.

51. Foster HM, Harris TJ. Malignant change (squamous carcinoma) in chronic chromoblastomycosis. Aust N Z J Surg. 1987;57(10):775-7.

52. Clayton J. Chagas disease 101. Nature. 2010;465(7301):\$4-5.

53. dos Santos VM, da Cunha SF, Teixeira Vde P, Monteiro JP, dos Santos JA, dos Santos TA, dos Santos LA, da Cunha DF. Frequency of diabetes mellitus and hyperglycemia in chagasic and non-chagasic women. Rev Soc Bras Med Trop. 1999;32(5):489-96. 
54. Corbett CE, Scremin LH, Lombardi RA, Gama-Rodrigues JJ, Okumura M. Pancreatic lesions in acute experimental Chagas' disease. Rev Hosp Clin Fac Med Sao Paulo. 2002:57(2):63-6.

55. dos Santos VM, de Lima MA, Cabrine-Santos M, de Stefani MD, de Araujo PG, Lages-Silva E, Ramirez LE. Functional and histopathological study of the pancreas in hamsters (Mesocricetus auratus) infected and reinfected with Trypanosoma cruzi. Parasitol Res. 2004;94(2):125-33.

56. Han XY, Zhang J, Li L. Leprosy Agents Mycobacterium lepromatosis and Mycobacterium leprae in Mexico: a Clarification. J Clin Microbiol. 2015;53(10):3387-8

57. Adhikari B, Kaehler N, Chapman RS, Raut S, Roche P. Factors affecting perceived stigma in leprosy affected persons in western Nepal. PLoS Negl Trop Dis. 2014;8(6):e2940.

58. Chaptini C, Marshman G. Leprosy: a review on elimination, reducing the disease burden, and future research. Lepr Rev. 2015;86(4):307-15.

59. Saraya MA, Al-Fadhli MA, Qasem JA. Diabetic status of patients with leprosy in Kuwait. J Infect Public Health. 2012;5(5):360-5.

60. Rui L, Aguirre V, Kim JK, Shulman Gl, Lee A, Corbould A, Dunaif A, White MF. Insulin/IGF-1 and TNF-alpha stimulate phosphorylation of IRS-1 at inhibitory Ser307 via distinct pathways. J Clin Invest. 2001;107(2):181-9.

61. Chen Y, Lu J, Huang Y, Wang T, Xu Y, Xu M, Li M, Wang W, Li D, Bi Y, et al. Association of previous schistosome infection with diabetes and metabolic syndrome: a cross-sectional study in rural China. J Clin Endocrinol Metab. 2013;98(2):E283-287.

62. Hays R, Esterman A, Giacomin P, Loukas A, McDermott R. Does Strongyloides stercoralis infection protect against type 2 diabetes in humans? Evidence from Australian Aboriginal adults. Diabetes Res Clin Pract. 2015;107(3):355-61.

63. Wiria AE, Hamid F, Wammes LJ, Prasetyani MA, Dekkers OM, May L, Kaisar MM, Verweij JJ, Guigas B, Partono F, et al. Infection with Soil-Transmitted Helminths Is Associated with Increased Insulin Sensitivity. PLoS One. 2015:10(6):e0127746.

64. Berbudi A, Ajendra J, Wardani AP, Hoerauf A, Hubner MP. Parasitic helminths and their beneficial impact on type 1 and type 2 diabetes. Diabetes Metab Res Rev. 2016;32(3):238-50.

65. Hussaarts L, Garcia-Tardon N, van Beek L, Heemskerk MM, Haeberlein S, van der Zon GC, Ozir-Fazalalikhan A, Berbee JF, van Dijk KW, van Harmelen $V$, et al. Chronic helminth infection and helminth-derived egg antigens promote adipose tissue M2 macrophages and improve insulin sensitivity in obese mice. Faseb j. 2015:29(7):3027-39.

66. Kamal SM, Turner B, He Q, Rasenack J, Bianchi L, Al Tawil A, Nooman A, Massoud M, Koziel MJ, Afdhal NH. Progression of fibrosis in hepatitis C with and without schistosomiasis: correlation with serum markers of fibrosis. Hepatology. 2006;43(4):771-9.

67. Pereira TA, Syn WK, Machado MV, Vidigal PV, Resende V, Voieta I, Xie G, Otoni A, Souza MM, Santos ET, et al. Schistosome-induced cholangiocyte proliferation and osteopontin secretion correlate with fibrosis and portal hypertension in human and murine schistosomiasis mansoni. Clin Sci (Lond). 2015;129(10):875-83.

68. Marin-Neto JA, Cunha-Neto E, Maciel BC, Simoes MV. Pathogenesis of chronic Chagas heart disease. Circulation. 2007;115(9):1109-23.

69. Machado FS, Tyler KM, Brant F, Esper L, Teixeira MM, Tanowitz HB. Pathogenesis of Chagas disease: time to move on. Front Biosci (Elite Ed) 2012:4:1743-58

70. Cunha-Neto E, Teixeira PC, Nogueira LG, Kalil J. Autoimmunity. Adv Parasitol. 2011;76:129-52.

71. Prado CM, Jelicks LA, Weiss LM, Factor SM, Tanowitz HB, Rossi MA. The vasculature in chagas disease. Adv Parasitol. 2011;76:83-99.

72. Falase $\mathrm{AO}$, Ogah OS. Cardiomyopathies and myocardial disorders in Africa: present status and the way forward. Cardiovasc J Afr. 2012;23(10):552-62.

73. Bohne W, Heesemann J, Gross U. Reduced replication of Toxoplasma gondii is necessary for induction of bradyzoite-specific antigens: a possible role for nitric oxide in triggering stage conversion. Infect Immun. 1994;62(5):1761-7.

74. Levy J, Espanol-Boren T, Thomas C, Fischer A, Tovo P, Bordigoni P, Resnick I, Fasth A, Baer M, Gomez L, et al. Clinical spectrum of X-linked hyper-lgM syndrome. J Pediatr. 1997;131(1 Pt 1):47-54.

75. Subauste CS, Wessendarp M, Smulian AG, Frame PT. Role of CD40 ligand signaling in defective type 1 cytokine response in human immunodeficiency virus infection. J Infect Dis. 2001;183(12):1722-31.
76. van der Werf MJ, de Vlas SJ, Brooker S, Looman CW, Nagelkerke NJ, Habbema JD, Engels D. Quantification of clinical morbidity associated with schistosome infection in sub-Saharan Africa. Acta Trop. 2003;86(2-3):125-39.

77. van Marck EA, Deelder AM, Gigase PL. Effect of partial portal vein ligation on immune glomerular deposits in Schistosoma mansoni-infected mice. $\mathrm{Br}$ J Exp Pathol. 1977;58(4):412-7.

78. Hillyer GV, Lewert RM. Studies on renal pathology in hamsters infected with Schistosoma mansoni and S. japonicum. Am J Trop Med Hyg. 1974;23(3):404-11.

79. Magnaval J, Glickman LT, Dorchies P, Morassin B. Highlights of human toxocariasis. Korean J Parasitol. 2001;39(1):1-11.

80. Li L, Gao W, Yang X, Wu D, Bi H, Zhang S, Huang M, Yao X. Asthma and toxocariasis. Ann Allergy Asthma Immunol. 2014;113(2):187-92.

81. Pinelli E, Dormans J, van Die I. Toxocara and asthma. In: Holland CV, Smith HV, editors. Toxocara: the enigmatic parasite. Oxfordshire: CABI Publishing: 2005. p. 42-57.

82. Cassell GH. Infectious causes of chronic inflammatory diseases and cancer Emerg Infect Dis. 1998;4(3):475-87.

83. Wjst M, Boakye D. Asthma in Africa. PLoS Med. 2007;4(2):e72.

84. Hahn DL, Schure A, Patel K, Childs T, Drizik E, Webley W. Chlamydia pneumoniae-Specific IgE Is Prevalent in Asthma and Is Associated with Disease Severity. PLoS One. 2012;7(4):e35945.

85. Poleshuck RTF, Bertti SC, Rubini N, Capelo AV, Da Silva EM, Sion FS, De Sa CAM. Total serum IgE levels and profile sensitization to dust mites in patients with asthma. World Allergy Organ J. 2015;8 Suppl 1:A140.

86. Mara D, Lane J, Scott B, Trouba D. Sanitation and Health. PLoS Med. 2010; 7(11):e1000363.

87. Meier CR, Jick SS, Derby LE, Vasilakis C, Jick H. Acute respiratory-tract infections and risk of first-time acute myocardial infarction. Lancet. 1998. 351(9114):1467-71.

88. Kuller LH, Tracy RP, Shaten J, Meilahn EN. Relation of C-reactive protein and coronary heart disease in the MRFIT nested case-control study. Multiple Risk Factor Intervention Trial. Am J Epidemiol. 1996;144(6):537-47.

89. Vallance P, Collier J, Bhagat K. Infection, inflammation, and infarction: does acute endothelial dysfunction provide a link? Lancet. 1997;349(9062):1391-2.

90. Rose JJ, Voora D, Cyr DD, Lucas JE, Zaas AK, Woods CW, Newby LK, Kraus WE, Ginsburg GS. Gene Expression Profiles Link Respiratory Viral Infection, Platelet Response to Aspirin, and Acute Myocardial Infarction. PLoS One. 2015;10(7):e0132259.

91. Generation25. The Water, Sanitation \& Hygiene Miracle in Nepal Kathmandu. 2014. http://generation25.org/2014/11/19/the-water-sanitation-hygienemiracle-in-nepal/. Accessed 5 Aug 2016.

92. World Health Organization Special Programme for Research and Training in Tropical Diseases: Community-directed interventions for major health problems in Africa: a multi-country study: final report. 2008.

93. Adhikari B, Mishra SR, Raut S. Rebuilding Earthquake Struck Nepal through Community Engagement. Front Public Health. 2016:4:121.

\section{Submit your next manuscript to BioMed Central and we will help you at every step:}

- We accept pre-submission inquiries

- Our selector tool helps you to find the most relevant journal

- We provide round the clock customer support

- Convenient online submission

- Thorough peer review

- Inclusion in PubMed and all major indexing services

- Maximum visibility for your research

Submit your manuscript at www.biomedcentral.com/submit 